\title{
THE COMPUTERIZATION OF MASS TORT SETTLEMENT FACILITIES
}

\author{
B. Thomas Florence* and Judith Gurney**
}

INTRODUCTION

A mass tort settlement facility must accomplish certain tasks that relate either to the terms of its charter ${ }^{1}$ or to business functions common to any large organization. To justify its existence, a settlement facility should be capable of disposing of large numbers of claims in a fair and equitable manner, and at an administrative cost that is less than the cost of conventional litigation. While computer technology offers a great opportunity to lower the transaction costs of processing claims and thus save money, nothing has the ability to deplete a facility's assets faster. Computer systems employed to process claims, which are called Management Information Services ("MIS"), are typically the second or third largest budget item in any settlement organization, lagging behind only personnel and, in some cases, physical plant.

Because these systems can become an organization's largest unproductive asset, the fit between the needs of the organization in each of its functional areas and the capabilities of the computer system to meet these needs is especially important in the computerization of mass tort settlement facilities. Settlement facilities should avoid, at all costs, a poor fit in either direction: (1) a system that cannot perform the analyses necessary in the time required or (2) an unnecessarily complex system for handling a simple task. To avoid these outcomes, decisions regarding computerization must begin with the identification of the organizational functions that the computer systems will support and conclude with the identification of the appropriate computer technology.

Part II of this article identifies and describes the five general functions that are required of a settlement facility. Part III then discusses the computer technology available to meet these five functions.

\section{Copyright $(\mathcal{1} 1990$ by Law and Contemporary Problems}

* Senior Vice President, Resource Planning Corporation; responsible for designing and implementing computer systems for the Manville Personal Injury Settlement Trust, the Dalkon Shield Claimants Trust, and the UNR Asbestos-Disease Claims Trust.

** Senior Research Analyst, Resource Planning Corporation.

1. The charter or trust agreement of a mass tort settlement facility such as the Manville Personal Injury Settlement Trust or the Dalkon Shield Claimants Trust is an integral part of the bankruptcy reorganization that describes and mandates the framework for claim settlements. 
II

\section{Mass Tort Settlement Facility Functions}

\section{A. Claimant Correspondence}

One of the most important functions of any mass tort settlement facility is establishing and maintaining close contact with the facility's constituency, or claimants. One of the first communication tasks a facility faces is contacting existing and, in some cases, potential claimants. In this initial contact, the facility must (1) explain why the facility was set up, what it is empowered by law to do, what it cannot do, and the constraints it faces in terms of time and money; (2) clarify the type of claims the facility is empowered to consider and what type it must reject; (3) inform claimants of the facility's policies on accepting and processing claims; and (4) explain the procedures the claimants must follow to initiate their claims and, if necessary, provide the claimants with the requisite forms to do so.

Once the facility has started processing claims, it must keep claimants informed of the progress of their claims and of any changes in the facility's policies and procedures for initiating and processing claims, or in its financial ability to meet claims. To satisfy these functions, the facility must establish and maintain an accurate mailing list over the facility's lifetime, and must have a means of mass producing letters, forms, and, if it wishes, newsletters to disseminate the necessary information.

Such claimant correspondence is not a simple function. The sheer number of claimants characteristically handled by mass tort settlement facilities can, by itself, create enormous problems. The Asbestos Claims Facility, for instance, dealt with 60,000 claims. The Manville Personal Injury Settlement Trust dealt with close to 17,000 claimants whose claims had been presented before the Trust was established, and expects to deal with at least another 150,000 claimants before its term runs out. The Dalkon Shield Claimants Trust expects to handle approximately 200,000 claims.

Mass tort claims also typically present a lengthy and emotionally fraught history. Many claimants have experienced a period of adversarial relations with employers and insurance companies. Employers, lawyers, union leaders, journalists, doctors, co-workers, family, and friends may well have offered claimants their opinions regarding whether the claimants suffered damage to their health, the cause of the claimants' symptoms, the course of action the claimants should take, and how much compensation they should seek or are entitled to recover. Many claimants are confused, suspicious, and often frightened. The settlement facility must therefore handle the claimants carefully and with consideration so they can understand, and accept, what the facility can offer them. The facility can present itself as a trustworthy organization only by communicating directly with its constituency. Absent effective communication, the probability of public and legal challenges to the operation of the facility increases exponentially. If, due to lack of communication, claimants feel that their claims are not being adequately 
reviewed or treated fairly, their fears and distrust may lead them to instigate public criticism of the facility and to support legal action against it.

Effective communication can also save costs. The cost of processing individual claims is directly related to the claimants' level of understanding as to what must be done to present claims. If, for instance, claimants do not understand that they must submit medical or financial records requested by a claim form, their claims will require special handling by settlement facility personnel before they can be processed or considered for settlement. Special handling necessarily means additional cost.

\section{B. Claim Status Tracking}

An equally important function of any mass tort settlement facility is tracking claims. Regardless of its specific charter, a settlement facility must be capable of determining the status of each claim filed with the facility. The facility may determine processing priority, for example, by the dates the claims were filed with the facility or by the claims' scheduled trial dates. In either case, the facility must establish and monitor claim-processing priorities. Whether settlement negotiations are spearheaded by a network of local counsel around the country or by claim reviewers at a central location, each facility must handle all claims according to strict rules and ensure that no claim is overlooked.

\section{Verification and Evaluation of Claims}

The primary function of any mass tort settlement facility is the evaluation of the validity and severity of each claim, and the establishment of a claim value. Although the evaluation process may be straightforward and amenable to representation by a set of simple rules when there are no issues of causation or liability, when these issues are a factor in assessing claims, and the settlement environment resembles that of a court of law, the function of verification and evaluation may demand a substantial commitment of the facility's resources.

Settlement facilities are intended to distribute compensation fairly and efficiently while reducing the transaction costs inherent in the litigation settlement process. As noted above, if a facility cannot meet these objectives, it cannot justify its existence.

\section{Management Analysis and Reporting}

Mass tort settlement facilities are required to plan and report financial outlays. These requirements fall into three functional areas:

1. Internal Audit. Settlement facilities must ensure that their procedures are producing fair and equitable settlements and that their employees and contractors follow all processing rules. To accomplish these objectives, the facilities must be capable of systematically auditing internal operations. 
2. External Reporting. All settlement facilities are responsible for reporting settlement progress to claimants or oversight entities. Whether the outside entity is the court, the funding source, the claimants, or the public, the facilities must be capable of demonstrating that they are meeting the requirements of their charter.

3. Actuarial Analysis. Although the nature of the actuarial analyses will differ according to the constraints placed on the specific facility, all settlement facilities must perform some actuarial function, such as forecasting cash demands, developing payment profiles or injury-payment schedules, and studying the feasibility of structured payment or insurance plans.

\section{E. Financial Control}

Settlement facilities have the same requirements as any public entity for adequate controls of their business operations and finances. In this regard, all facilities must have provisions for general accounting and bookkeeping, accounts payable, payroll, tax, and check writing, as well as asset management.

\section{III}

\section{Computer Technology to Meet Settlement Facility Functions}

\section{A. Claimant Correspondence}

There is little doubt that current computer technology provides enormous advantages for the tasks related to communicating with claimants. With claimant populations in the thousands, it is economically infeasible to contemplate manual methods for these tasks. Relatively simple computer programs can develop and maintain accurate mailing lists and prepare personalized standard letters. Desk-top computer technology can create letters, forms, and pamphlets that equal typeset quality.

The cost to the facility of using computer technology for claimant correspondence depends almost entirely upon the scale of the task, that is, whether it is dealing with 1,000 letters per week or per minute. The nonobvious, but in some instances substantial, costs associated with this function arise from the personnel required to maintain current data.

In addition to its generalized correspondence, the settlement facility may have to provide claimants with a means of personal, and perhaps verbal, contact, which will necessarily generate additional personnel costs. This is more necessary in cases where claimants have difficulty reading or understanding written English, where claimants do not have legal representatives, or where the settlement process prior to the establishment of the facility has been acrimonious. 


\section{B. Claim Status Tracking}

When the number of claimants exceeds several hundred, it is virtually impossible to track the status of claims cost effectively without some form of computer support. Even at the most rudimentary level of claims processing, a settlement facility must obtain certain data for each claimant: (1) the identity of the claimant and any identifying characteristics; (2) the nature of the claimant's allegations; (3) the organization's belief about the claimant's allegations; (4) the status of the claim in the initiation, review, and settlement process; and (5) the settlement amount paid to the claimant. The level of detail desired in each of these areas and the size of the claimant population determine the computer resource requirements. For example, if the organization has a maximum of 5,000 claimants, each of which requires the equivalent of only one page of information, tracking the status of the claims could be performed easily on personal computers. It may be necessary, however, to maintain a more extensive file on each claimant. For example, depending on the nature of the tort, a facility may need to know each claimant's residential, employment, medical, and litigation histories. Moreover, if claimants are members of a group seeking compensation through a group settlement, the settlement facility will have to maintain certain group data in each claimant's file. At the very least, the facility must somehow link the claims of group members as they pass through the settlement system.

If claimants will be required to submit proof of their claims in the form of medical, employment, or personal financial records, the settlement facility must maintain a system to track the arrival of the records. The facility must also maintain a system to track the arrival of the proofs, tests, or records produced by any of its own claims investigations. Finally, if claimants can appeal from the decision of the settlement facility, the facility must track the status of the claim through the appeals process.

When a network of local counsel in different geographic locations handles settlement negotiations, the question of who enters into the computer the information essential to tracking the status of claims can be problematic. If this disperse data needs to be coordinated, the facility must establish a tracking system with similar data classification and entry forms at every entry point.

The ability of a number of computer software packages to perform the tasks involved in claimant status tracking is well defined and tested. The complexity and cost of putting all the parts together, however, is much greater than in the case of a claimant correspondence system. If the settlement facility is required to maintain ten to twenty pages of information on 200,000 claimants, the necessary computer system could cost as much as $\$ 2$ to $\$ 3$ million. A facility should therefore proceed slowly in this area and spend ample time deciding its precise requirements. It must analyze, in detail, what data are absolutely necessary to (1) identify a claimant, (2) keep track of a claim, (3) identify similar claims, and (4) identify trends and 
problems in the settlement process. Two or three design decisions, taken lightly, can turn a $\$ 15,000$ system into a $\$ 1.5$ million system.

\section{Verification and Evaluation of Claims}

Computer systems can save a settlement facility the most money in its primary business function, that is, in verifying and evaluating claims. In this context, computer systems reduce the need for personnel, which, as noted above, is typically the largest line item in a settlement facility's budget. However, the use of computer systems to satisfy this function is also the area in which computer systems have been tested the least and characteristically do not live up to their potential. As a result, while computer technology offers a great opportunity to lower the transaction costs of verification and evaluation of claims, and thus save money, nothing has the ability to deplete a facility's assets faster. These computer systems, or "expert systems," as they have come to be called, can become a facility's largest unproductive asset.

Despite this danger, these computer systems can be very useful in carrying out comparisons and calculations that aid a facility's claims verification function. For example, to verify a claimant's exposure to Agent Orange, the Agent Orange facility could use a computer system to compare the claimant's statement of military assignments in Vietnam with records of herbicide dissemination. Similarly, the Manville Trust could use a computer system to compare a claimant's exposure to asbestos with the claimant's employment history and records of asbestos use in different industries and occupations.

MIS systems, such as "expert systems," can also be very useful in evaluating claims in different contexts. For example, (1) where settlement amounts are pegged to historic settlement figures, a computer system can compare a claim with all previously settled claims of similar characteristics, and determine the range and most likely settlement value of the present claim; (2) where plaintiff attorneys and other experts agree upon the rules to be used in the valuation of a claim, the facility can program its computer system to apply these logical rules and calculate claim values; and (3) where a settlement process is required to mirror values that would accrue in the tort system, the facility can use a computer system to construct a statistical model of prior settlements and apply this model repeatedly as a guide to settlement negotiation.

Further, when a direct link has been established between symptom and exposure, a computer system could perform automatic calculations of settlement amounts. In the DDT Settlement Fund, for example, a computer system could compare the actual blood DDT level of a claimant to background (normal) levels of blood DDT in the population, and multiply this factor by a given dollar amount to obtain a base settlement figure.

It is easy, however, for a facility to be so enamored with the possibilities of an MIS system that it over-designs the computer support. In other words, a facility may design a 747 jetliner where a bicycle would do the job. To select the appropriate MIS system, the facility must first establish the quantity of 
data and types of decisions required to verify and evaluate claims, and determine the interrelationships within this data-that is, whether the validity of one piece of datum is dependent on another piece. In making these determinations, the facility must consider numerous issues, such as:

1. Clarity of Guidelines. Are the guidelines for eligibility and compensation adequately clear?

2. Payment Categories. Were payment categories settled before the facility began operating?

3. Prior Settlement Data. Are settlement data available in a reliable form for the type of claims the facility will consider, and have these data already been statistically analyzed?

4. Claimant Pool Characteristics. Is the present number of claimants final or are more claimants expected in the future? Will future claimants, if any, have different characteristics from the present claimant population? Will the facility consider future claims of illness or injury from current claimants?

5. Characteristics of Illnesses and Injuries. Are the medical illnesses and injuries eligible for compensation few or many, and easy or difficult to diagnose? Are there multiple possible causes for the medical illnesses and injuries for which claimants can request compensation? Are the medical illnesses and injuries easily categorized?

6. Exposure Criteria. Have exposure criteria, defining the conditions under which a claimant may have suffered compensable injury, already been developed? If so, are they consensual? Does exposure depend on extensive time periods in a given location or occupation? Are there degrees of exposure related to different medical illnesses and injuries?

7. Claims Investigation. Will individuals or panels of experts investigate the claims? If so, what procedures will be used to conduct and report the investigations?

8. Documentary Evidence. Does prior documentation, such as discovery, exist, pertaining to the eligibility of the claims under the settlement facility's charter? If so, what role will such documentation play in the evaluation of the claims?

9. Factors Affecting Recovery. What factors, other than the claimant's illness or injury, will the facility consider in determining compensation. (for example, economic effects that could depend on age, salary, extent of disability, and number of dependents)?

10. Appeals Process. Will the facility have an appeals process for claimants, and, if so, what will the process involve? 
11. Timing of Claims. Will the expected claims be filed at an even pace, or will the facility experience a great crush of claims at the beginning?

12. Quality Control. What type of quality control system will the facility need?

A final word of caution is necessary regarding the use of computer technology to evaluate mass tort claims. This use of computers is on the cutting edge of technology and the law. Legal logic may not conform to computer logic, and claim settlement logic does not always conform to any system of logic. Computer applications in this area are high-risk, high-payoff endeavors. A mass tort settlement facility should implement a computer system only after extensive planning and consideration of the contingencies that would result if the system failed to do that which was expected of it.

\section{Management Analysis and Reporting}

A settlement facility will likely have no choice regarding the use of computer systems to carry out its management analysis and reporting functions. Given the requirement set down in their charters to report to external oversight organizations, all facilities will need some form of computerized analytic capability. Virtually the only factor influencing the type and cost of system a facility uses is the format and volume of information to be stored on the computer, and thus available for analysis and reporting. A relatively simple and inexpensive computer system can handle small volumes and straightforward data entries. For example, because of the limited information available to the DDT Settlement Fund and the simplicity of its payment scheme, a skilled individual and a personal computer could satisfy its analytic requirements. On the other hand, a sophisticated and expensive computer system is needed to handle a large volume of information and complex data entries. For example, during its bankruptcy proceeding, A.H. Robins was required to maintain a fifty-page claim form for each claimant as well as every pertinent medical record either requested by or submitted to the court in support of the claim. The analytic system built to manage this task cost millions of dollars, and each analysis it conducted required a massive amount of computer resources.

Although the DDT Settlement Fund and the A.H. Robins bankruptcy proceeding represent the two extremes, they illustrate the importance of precisely determining the data required to satisfy all internal and external analysis and reporting needs.

\section{E. Financial Control}

The function of controlling finances was one of the first commercial applications of computer technology. Today, using computers to manage finances is so widespread that even local "mom-and-pop" corner stores probably use computers to carry out their financial controls. This application 
of software systems is well documented and tested, and, because of its long history, is also one of the most cost effective.

A competitive market exists for computer hardware and software designed to handle financial support functions in-house. Settlement facilities, however, should consider the possibility of using an outside service bureau that specializes in accounting procedures to manage its finances rather than relying completely on in-house computing systems. Because of the maturity and competitiveness of the external, financial computing market, it might be more cost effective to pay a bank or a service bureau to handle functions such as check writing, asset management, and payroll.

\section{IV}

\section{Conclusion}

A mass tort settlement facility can use a computer system to support organizational functions. The key word here is "support." The facility should not consider the use of computer technology until it has designed the process to be supported. That is, the facility must first precisely determine the number and characteristics of claimants, and how much, when, and how claims will be settled. Only then is it reasonable to ask the question, "Can the computer help us do this more efficiently?" 
